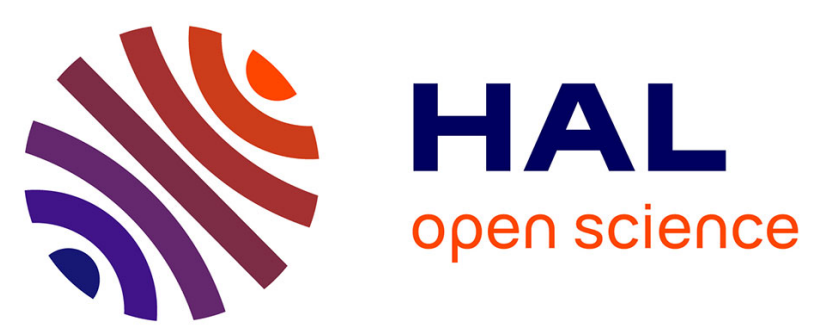

\title{
Empirical identification of perceptual criteria for customer-centred design. Focus on the sound of tapping on the dashboard when exploring a car
}

François Montignies, Valery N. Nosulenko, Etienne Parizet

\section{- To cite this version:}

François Montignies, Valery N. Nosulenko, Etienne Parizet. Empirical identification of perceptual criteria for customer-centred design. Focus on the sound of tapping on the dashboard when exploring a car. International Journal of Industrial Ergonomics, 2010, 40, pp.592-603. 10.1016/j.ergon.2010.04.004 . hal-00849425

\section{HAL Id: hal-00849425 \\ https://hal.science/hal-00849425}

Submitted on 31 Jul 2013

HAL is a multi-disciplinary open access archive for the deposit and dissemination of scientific research documents, whether they are published or not. The documents may come from teaching and research institutions in France or abroad, or from public or private research centers.
L'archive ouverte pluridisciplinaire HAL, est destinée au dépôt et à la diffusion de documents scientifiques de niveau recherche, publiés ou non, émanant des établissements d'enseignement et de recherche français ou étrangers, des laboratoires publics ou privés. 


\title{
Empirical identification of perceptual criteria for customer-centred design. Focus on the sound of tapping on the dashboard when exploring a car
}

François MONTIGNIES $^{(a)}$, Valery NOSULENKO ${ }^{(\text {b) }}$, Etienne PARIZET ${ }^{\text {(a) }}$

(a) : Laboratoire Vibrations Acoustique, INSA-Lyon, F-69621, France

(b) : Psychology Institute, Russian Academy of Sciences, Moscow, Russia.

Corresponding author :

Etienne Parizet, Laboratoire Vibrations Acoustique, INSA-Lyon, F-69621, France, email : etienne.parizet@insa-lyon.fr

\begin{abstract}
This work results from a demand made by a car manufacturer (Renault) relating to a phenomenon whose impact on customer perception is only suspected : the sound of the dashboard when tapped in a show room. To identify which perceptual criteria are really relevant for customer centred design, an empirical observation of customers exploring vehicles was set-up. The operations performed, the perceptions verbalized and the different elements of the vehicle targeted were analyzed from a qualitative and a quantitative point of view. In this paper, the data were firstly examined to obtain an appreciation of customers' global behavior. The study had then to focus on the dashboard, to observe if the act of tapping occurs in a real context and identify the possible influence of the resulting sound on perception.

Relevance to industry :

Empirical observation results in databases about activity and perception of potential customers exploring a car. These ones can be used by Renault to identify pertinent perceptual criteria to include in a customer-centred design process. The focus on the dashboard more specifically demonstrated the benefit car manufacturers can obtain by working on the sound of tapping.
\end{abstract}

Keyword : customer centred design, cognition, perception

\section{Introduction}

Many industrial companies have taken a customer-centred approach in order to optimise the attraction of a product before purchase or customer satisfaction during use. This approach implies integrating human factors at the heart of the design process, that is to say placing the customer's experience of the product at the forefront of concern. This experience is based on the interaction between a subject and an object. Therefore, it is constituted by subjective dynamics (emotion, action and perception), and can lead to different subjective responses (affect, behaviour, and cognition; [1]). These responses can be investigated by different approaches: kansei engineering ([2]), usability ([3]), product semantics ([4]), and perceived quality ([5]), among others. The framework adopted here is to consider that perception reflects the different aspects of subjective experience, including affect and behaviour, when attributing perceived qualities to the object. Thus designers can benefit from a good definition of the perceptual criteria to be included in the design process. Essentially, a perceptual 
criterion can be described by three components: the subjective evaluation to be managed, the sensorial medium by which it is perceived, and the perceived design element to be developed. The starting point of customer-centred design is to define the general subjective identity of a product, as in the zero level of kansei engineering ([2]). This stage may be driven successfully by the standpoints taken by the designers or marketing teams. However, when advancing to the following levels that include the expression of this identity in perceptual criteria, divergences between customers and designers can occur. Differences between designers' and users' perceptions of a specific criterion, the product form, have been highlighted in [6]. To go further, not only the description but also the identification of the perceptual criteria should be based on customers' perception. Nevertheless, in most studies of customer perception, designers define perceptual criteria from the outset. For example, the studies described in ([7]), ([8]) and ([9]) focused on the visual aesthetic impression of product form. It might be assumed that it is a pertinent perceptual criterion, but these works do not deal in any way with the relative importance of this human factor in product perception. In kansei engineering, an expert system is able to provide information about the links between an affect and a design element. However, the results can be vague for complex products. For example, it has been pointed out that an expert system was able to link styling perception to car interior but failed to identify the importance of a more specific design element ([10]).

Finally, it is difficult at present to find studies that attempt to fully define perceptual criteria from the customer's point of view. Nevertheless, by neglecting this stage, designers run the risk of overlooking criteria felt important by the customer or, on the contrary, they may waste time on others not perceived in a real situation. Perceptual criteria can also suffer from poor definition of its three components (subjective evaluation/sensorial medium/design element). Customer self-reports were used in ([11]) to show that, despite the overriding importance given to visual cues in product evaluation, other sensorial modalities and thus less obvious perceptual criteria had to be studied carefully. Therefore identifying the design elements to work on is not an easy task. It depends on the complexity of the object, and a single detail might play an important role in the evaluation of the product as a whole. Lastly, a subjective evaluation cannot be defined merely as a simple response of agreement or disagreement. Customers' judgments can be driven by affects, symbols and semantics ([1]) and thus aim at different qualities: functionality, hedonism, reliability and so on. Moreover, a perceptual criterion must be grounded in a corresponding context of interaction. [12] suggest that the respective influence of each modality evolves at various stages of user-product interactions. The same conclusion remains valid for the design element and the nature of evaluation.

In the case analysed here, Renault had already targeted a very specific perceptual criterion: the impact of the noise made in show-rooms by customers when tapping on a car dashboard. The company wanted to identify an acoustic metric that would predict the subjective evaluation of the sound, as performed for the noise of closing a car door ([13]), or building a satisfaction model of the materials used in passenger car interiors that would include audition in addition to vision and touch ([14]). However, to our knowledge, no study has been carried out in a real situation, so that the real occurrence of the act of tapping and its influence on customer perception remain unknown.

This is the reason why it was decided to move upstream in the process. In order to identify the perceptual criteria important for the customer while they examine a static vehicle in a show-room, several questions had to be addressed. Which customer/product interactions occur in a real situation? What perceptual phenomena are customers mostly interested in? What judgement criteria and sensorial data do customers base their perception on? And, finally, which sources produce the stimuli? To achieve this goal, an empirical study was performed. It consisted in observing a commented activity in a realistic situation. The free exploration of static vehicles and simultaneous free verbalisations were recorded by an 
audiovisual device. A qualitative study led to the creation of a hierarchical data analysis grid, by bringing to light different categories of operations and perceptions. The addition of quantitative and statistical processing made it possible to describe the relative importance of different operations and perceptions. It was then be possible to determine whether the act of tapping on the dashboard emerged naturally as a relevant human factor that could be linked to a perceptual criterion.

\subsection{Data collection}

\subsubsection{Methods in ergonomics}

Ergonomics is undoubtedly the discipline most involved in the empirical study of the interaction between a subject and the objects in their environment. It calls on different methods ([15]; [16]) in order to identify decisive human factors for product design on the basis of a representative sample of potential users. Some focus on collecting what subjects have to say about their experience with an object while others are intended to observe the situation in which interactions occur.

Mention can first be made of the focus-group, a qualitative evaluation method mainly used in marketing and applied social sciences. The aim is to bring to light pertinent information from a group discussion coordinated by a moderator. Regarding product evaluation, this method can provide more or less accurate information about the perceptual phenomena of interest, if the discussion is efficiently oriented towards the real interaction experience. The objective of the discussion can be to simply recount one's experience, imagine an ideal product or, for example, evaluate prototypes.

It is also possible to use interview techniques. The latter mainly stem from clinical or social psychology and have different variants: directive, semi-directive (or structured) or nondirective (also known as free or in-depth). Interviews can be used alone but are more effective when they complete the observation of a product use situation in the laboratory or in a real situation. Interviews can also use traces such as recordings of an observation (video or audio), still with the aim of permitting the participants to project themselves in a situation or real interaction. One interview methodology is to be mentioned. Based on personal construct psychology, repertory grids are used to determine costumers' perception of a product ([17]). Several stages are needed for an application fully based on subjective data. First, interviews partly based on comparison tasks are held. They aim at identifying the elements and the constructs mainly involved in the perceptual image of a product. These elements are then rated on bipolar scales representing the associated constructs.

The origin of laboratory observation is rooted in experimental psychology. When centred on usage, the term "user test" is used. In this case the characteristics of the object are varied and measurements made of performance indicators such as efficacy (number of errors/goals reached) and efficiency (time to carry out a task). In addition, a subjective measurement of satisfaction is often made by recording the user's preference. According to standard ISO 20282 [3] usability can be defined by efficacy, efficiency and satisfaction. Certain studies go further by collecting subjective data often through verbal protocols. For example, it is possible to record verbalisations simultaneously with the actions they accompany, by free verbalisations spoken aloud, or following use, by different types of interviews.

Observation in "real-life" situations is inspired by ethnology. It consists in observing users in their real activity in natural situations, or clients at places of sale. Two main categories of observation can be distinguished. One consists of a simple observation for which the subject is directly involved in the collection of information. The ethnologist carrying out the observation can film the activity and even sometimes stop it punctually to question the 
participant. The other consists of consecutive interviews with or without the help of traces. Data can also be collected at the same time as the activity, via spoken verbalisations (commented activity).

This non-exhaustive list of ergonomics methods gives an overview of different kinds of approaches used to listen to or observe the customer. The goal of this study was to focus on a real interaction situation and understand customers' perceptions. It therefore required a methodology that allowed listening to the customer and observing them at the same time, during their discovery of the vehicle.

\subsubsection{Specific approach}

An original framework can be provided by the psychology of engineering, as developed in Russia. V. Nosulenko and E. Samoylenko have proposed methodological tools for collecting and processing data that reveal both the activity and the perception of a subject in interaction with an object. Using Russian theories on man-technology interaction ([18]) and the Cognition and Communication Approach (CCA) as their basis ([19]), they use a comparative task to collect data about the user/customer. The subjects' operations are used to describe the interaction. Their verbalisations are used to describe the object of an interaction by a number of perceived qualities. This approach has been used to evaluate technological artefacts by observation in real-life situations ([20]). On the other hand, many publications have established perceptual profiles of objects on the basis of laboratory tests. They deal with environmental noise ([21]), musical timbres ([22]), and the sounds of car engines ([23]).

This approach was chosen because, contrary to repertory grids, no scaling stage is needed. Consequently, no a priori assumption about the perception of the product by subjects is made. Information is extracted from the observations of participants. To this end, a protocol for data collection was developed and resulted in the collection of relevant data about activity and perception in the specific context, i.e. the evaluation of a product in a showroom.

\subsubsection{Guidelines for the data collection method}

The observation follows two main guidelines for the collection of relevant data on activity and perception in the specific context, i.e. the evaluation of a product at a sales point.

First, the observation must be ecologically valid, i.e. the empirical study must be performed using all the participants in situation, under realistic material and psychological conditions. Minimal material conditions are satisfied by the use of real products. When possible, it is even better to perform the empirical study in a real material environment. Setting the appropriate psychological conditions allows the participants to project themselves in the context. In particular, the participants have to perform their activity following a clear goal, i.e. choose a product to purchase. However, the task proposed to the participants must leave them free to explore products as they wish. Under these conditions, it is assumed that the participant's actions will conform to what may occur in a real situation and allow us to draw close to an ecologically valid activity.

Secondly, the Cognition \& Communication Approach (CCA, [19]) proposed that verbalisations were good indicators of perception in a situation of comparison. Therefore, the instructions of the empirical study must suggest to the participants that they express themselves freely during the activity. To start comparison, at least two products have to be presented at the same time. Note that the goal of the comparison has to correspond to the goal of the activity. Since the goal is to choose a product to purchase, the comparison here is implicit. Although it is not possible to quantify in absolute terms that such and such a product has such and such a quality, it is assumed, in line with the CCA hypothesis, that the verbalizations recorded from the participants' free speech will reveal the nature of the discriminative perceived qualities in the activity observed. 


\subsubsection{Raw data}

Exhaustive audiovisual recording of all the participants' operations and verbalizations during the activity observed can be used for the analysis, but before any data processing, it is necessary to identify and format the units of information to be analysed.

The operations are minimal segments making up the subject's activity. They can be directly extracted from video viewing and take the form of a textual description taking up the heading of one row in a database dedicated to the activity.

The verbal units are segments of verbalizations expressed by the participants. The segments specifically selected for the analysis presented are the propositions that qualify the product or parts of the product (e.g. "I think the design of the car is outdated", "This button is useless, I definitely won't use it", "The black panel..."). They are meanings of the products, not from the point of view of the designer as in product semantics ([3]), but as qualities perceived by the subject. The entire discourse is kept as an empirical framework for the semantic interpretation of the verbal units. Thus, verbal units are extracted from the complete textual transcriptions of the audio recording. Each verbal unit takes up the heading of one row in a perception database .

Each verbal unit and each operation is initially linked to a participant and a vehicle. They are described by a set of variables in the databases after qualitative analysis.

\subsection{Qualitative analysis}

This stage of the methodology is used to build a database that retranscribes the customers' actions and perceptions as well as the objects specifically focused on by the exploration.

Since the participants could freely act and express themselves, the units of collected information have to be coded within qualitative categories, so that the phenomena of interest can be subjected to interpretation and quantified description. No predefined analysis grid is used. Analysis categories are built from two steps of open coding: basic coding and ontological coding. Furthermore, two different interpretation grids are built: one for the operations and one for the verbal units.

In what follows, a specific notation is used to distinguish the coding fields or observed variables, noted <variable>, and the modalities they can have, noted <modality>.

\subsubsection{Basic coding}

It is first necessary to link each of the operations and each of the verbal units to an <object>, i.e. the item of the product specifically targeted.

For the forms of empirical data that are a priori all different, whether for the operations or verbal units, the aim is then to identify categories that group data with equivalent meanings at a basic level. These categories are the qualitative modalities of a field named <basic operation > for operations and <basic descriptor> for verbal units.

Regarding the verbalizations, the coding must reveal the underlying information expressed by the verbal unit regarding the perceptual image built by the participant. To do this, the logic form of the verbal unit and the meaning that it conveys are coded in several fields. No details of the coding of the verbalizations are provided in the framework of this article. However, most of the fields used correspond to those presented by [19]. Some have been added because of the specific topic of this study. The <sense> field indicates whether a particular sensorial modality is explicitly linked to the verbal unit. The <aspect> field indicates whether the verbal unit refers to the <global $>$ object or to a more specific design element (<matter $\rangle$, <shape>, <colour>). 


\subsubsection{Ontological coding}

This second phase is called "ontological", since it corresponds to the organisation of basic categories in relation to each other, as a structured set of concepts that give meaning to the information. Different levels of abstraction have to be defined, thereby determining hierarchically organised categories. The analysis categories are built in such a way as to ensure convergence between empirical data and theoretical hypotheses. Thus the processing performed here belongs to the induction and deduction principles of Grounded Theory construction ([24], [25], [26], [27], [28]). Hypotheses from certain theories of perception were used since the aim of this research was to study perception in activity. .

\subsection{Quantitative processing of qualitative data}

\subsubsection{Indicators for the activity}

Processing data related to the activity consists in calculating the occurrences and the durations of different operations identified when watching the video recording.

\subsubsection{Indicators for the verbalizations}

Processing data from the verbalizations (coded verbal units) consists in calculating for each participant the number of occurrences of each verbal category as well as its trend.

In order to compare the different verbal categories, the number of occurrences is normalised in comparison to the average production of verbal units produced by each participant.

The trend is an indicator that was initially formulated in [19] to quantify the valence (positive/negative) of the semantic content in a set of verbal units.

For a given verbal category (e.g.: <robustness>), let $\left(N_{p}\right)$ be the normalised number of occurrences of verbal units of affirmative valence (e.g.: "this bumper makes it look rugged ") and $\left(N_{n}\right)$ be the normalised number of occurrences of verbal units of negative valence (e.g. "I think it's fragile”), then:

- $\Delta$ is the difference of valence in the set of verbal units expressing this category:

$$
\Delta=N_{p}-N_{n}
$$

- $k$ is the weight of this difference in the set of verbal units expressing this category:

$$
k=\frac{|\Delta|}{N_{p}+N_{n}}
$$

- $T$ is the trend of this verbal category in the set of verbal units:

$$
T=k \times \Delta
$$

\subsection{Application to the specific industrial problem}

In a subjective experiment, focusing on a predefined perceptual criterion or on a more basic object makes it possible to use a larger number of samples. However, the complexity of the product studied here led us to limit the comparison task to two vehicles. In fact, a car is composed of many subparts with many potentially perceived qualities. Furthermore, the duration of a comparative experiment as well as the amount of collected data rise exponentially as the number of objects to be compared increases. 
Nevertheless, the limited number of vehicles compared has a minor impact within the scope of this study. The aim was not to establish and quantify the perceived profile of such or such a vehicle. In our case, the main goal was to identify perceptual criteria that might be relevant for considering the subjective image of a vehicle. More samples could have been used if we had focused on the dashboard or on sound, but this predefinition would have led to the results being out of context. What is more, it would not have been possible to conclude whether the noise, in particular, of the dashboard, in particular, has a significant impact on perception.

Figure 1 provides a synthetic presentation of the methodology as it was applied to study the exploration of immobile vehicles by potential customers.

\begin{tabular}{|c|c|}
\hline \multirow{3}{*}{$\begin{array}{l}\text { Data } \\
\text { collection } \\
\text { (3.1) }\end{array}$} & $\begin{array}{c}\text { Experiment } \\
\text { Comparison of } 2 \text { immobile vehicles freely explored }\end{array}$ \\
\hline & $\begin{array}{c}\text { Raw data collection } \\
\text { Activity: Video recording of free activity } \\
\text { Percention : Audio recording of free verbalization }\end{array}$ \\
\hline & $\begin{array}{c}\text { Raw data formatting } \\
\text { Discrimination of objects targeted,, operations and verbal } \\
\text { units, for each of the subject }\end{array}$ \\
\hline \multirow{2}{*}{$\begin{array}{l}\text { Qualitative } \\
\text { analysis } \\
(3.2)\end{array}$} & $\begin{array}{c}\text { Basic coding } \\
\text { Design of basic analysis categories for objects targeted, } \\
\text { operations and verbal units }\end{array}$ \\
\hline & $\begin{array}{l}\text { Ontological coding of basic categories } \\
\text { Design of analysis categories hienarchically organized, for } \\
\text { abjects targeted, operations and verbal units }\end{array}$ \\
\hline \multirow{2}{*}{$\begin{array}{c}\text { Quantitative } \\
\text { analysis }\end{array}$} & $\begin{array}{l}\text { Calculation of indicators for perceptual dynamics (3.3) } \\
\text { Activity: Occurrence et duration as a function of the } \\
\text { operation and the object targeted } \\
\frac{\text { Perception :Occurrence and trend as a function of the }}{\text { verbal category and the object targeted }}\end{array}$ \\
\hline & $\begin{array}{l}\text { Focus on the act of tapping (4) } \\
\text { Perception: Occurrence and trend for verbal categories } \\
\text { linked to the dashboard } \\
\text { Activity: Occurrence for operations linked to the } \\
\quad \text { dashboard } \\
\text { Synthesis: Relation between operations and verbal trend } \\
\text { linked to the dashboard }\end{array}$ \\
\hline
\end{tabular}

Figure 1. Application of the method to the exploration of an immobile vehicle

\section{Potential customers exploring immobile vehicles}

\subsection{Data collection}

\subsubsection{Participants}

For the sake of simplicity, the empirical study was conducted in the Renault Technocentre and the participants were selected from the staff. Nevertheless, they were selected on the basis that their job was not related to design, customer perception, quality evaluation and so on.

Seventy participants were convened. They were originally selected according to gender and age criteria based on the statistical data compiled by Renault's Product Management. However, abandons and last minute reshuffles prevented us from reaching the desired proportions. The sample was finally composed of 31 men and 21 women. Ages extend from 20 to 59 , with a mean at 38 . 


\subsubsection{The vehicles}

The vehicles explored by the participants were two small urban vehicles of similar price: $\langle V 1\rangle$ and $\langle V 2\rangle$. Moreover, neither of the two cars was a Renault, thus avoiding any bias due to affiliation.

\subsubsection{Configuration}

Figure 2 shows a top view of the experimental set-up, with the positions of the vehicles and the 2 steps preceding the exploration as such. The vehicles remained immobile throughout the observation, without it being possible to start the engine, as in a showroom. The vehicles were arranged head-to-tail in order to facilitate the passage of the participants from one driver's seat to the other.

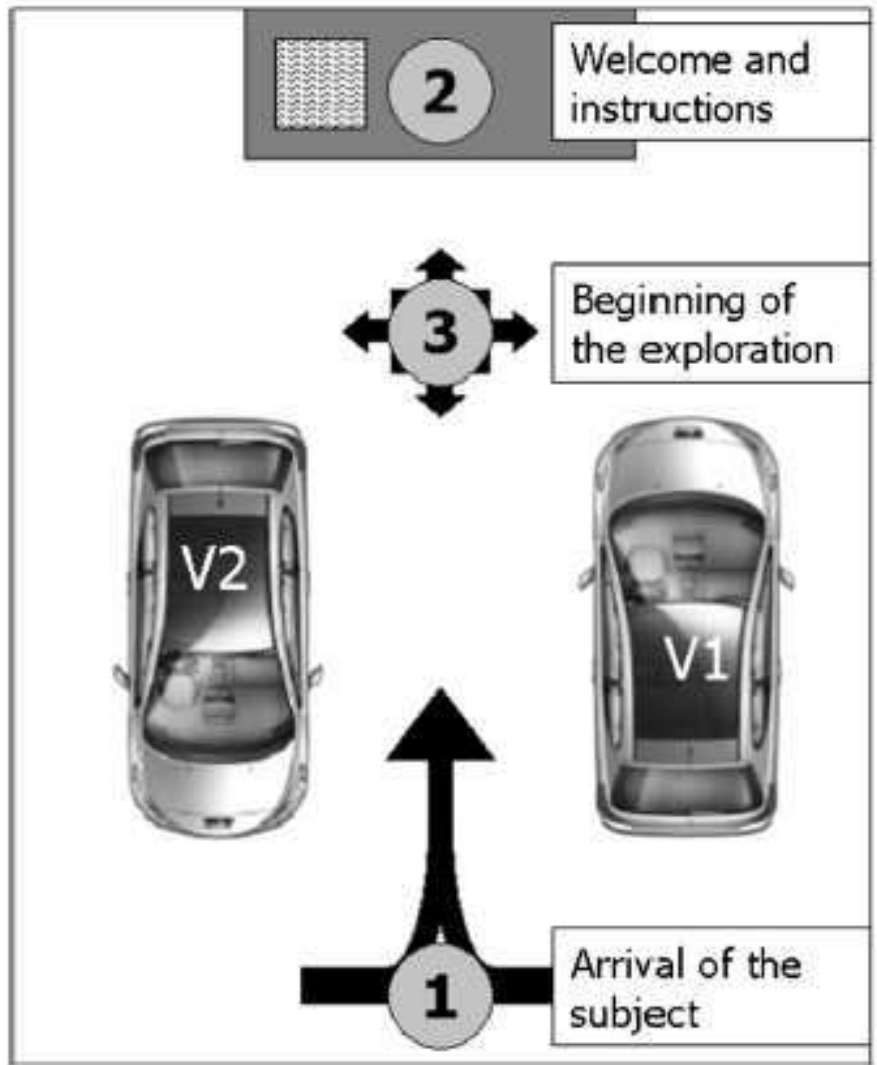

Figure 2. Configuration of the empirical observation

\subsubsection{Instructions}

The subjective conditions of the study were prepared by questioning the participants about their expectations by email sent several weeks before the empirical observation. This entailed asking them to freely list their main expectations, by order of priority, of a city car they had to imagine they wanted to purchase. Each participant was then asked to explore the two vehicles with the sole instruction of choosing that which they would prefer to purchase. They were therefore free to act as they wished. They were" also told that they could speak freely during the exploration. The time spent by an individual to explore the vehicles was considered as having ended when they clearly declared their preference.

It was therefore possible to determine three main phases for this empirical study: conditioning by preliminary survey; observation during freely commented free exploration; and, lastly, decision-making via the expression of a preference, possibly with reasons why. 


\subsubsection{Raw data}

The participants were filmed by digital camera during their explorations. 9995 operations were then extracted from all the video recordings.

The participants wore lapel microphones linked to a miniature digital recorder that they could carry in their pockets. Afterwards, 5900 verbal units were extracted from the textual transcriptions of the recorded verbal data.

\subsection{Qualitative data analysis}

The method described in 2.2. is applied here, that is to say an open code with two phases: basic coding and ontological coding.

\subsubsection{The objects targeted}

A vehicle is a complex object that the participant can consider as a perceived unit, though most of the time they focus on sub-elements, making the latter the objects of perception. A three level hierarchy of objects was built during the ontological coding phase : <Main part>, <Object>, < Details>. Another field allowed coding spatial information about the localization of the coded objects. The two main coding categories are given in table 1 .

\begin{tabular}{|c|c|c|c|c|c|}
\hline \multirow{2}{*}{$\frac{\text { <coding category }}{\text { Main parts }}$} & \multicolumn{5}{|l|}{$<$ modality $>$} \\
\hline & Interior & Exterior & Boot & Engine & Interior or Exterior \\
\hline Basic objects & $\begin{array}{l}\text { Fuse box } \\
\text { Belt } \\
\text { Handbrake } \\
\text { Speaker } \\
\text { Light button } \\
\text { Gear lever } \\
\text { Sun visor } \\
\text { Remote bonnet release } \\
\text { Remote fuel-filler } \\
\text { door release } \\
\text { Pedals } \\
\text { Dashboard } \\
\text { Storage space } \\
\text { Seat } \\
\text { Control panel } \\
\text { Instrument cluster } \\
\text { Steering wheel } \\
\text { Floor }\end{array}$ & $\begin{array}{l}\text { Antenna } \\
\text { Body } \\
\text { Fuel-filler door } \\
\text { Wheel } \\
\text { Bumper } \\
\text { Lights } \\
\text { Windshield } \\
\text { wiper }\end{array}$ & $\begin{array}{l}\text { Storage space } \\
\text { Jack } \\
\text { Mat } \\
\text { Parcel shelf } \\
\text { Spare wheel }\end{array}$ & $\begin{array}{l}\text { Bonnet } \\
\text { Bonnet stay }\end{array}$ & $\begin{array}{l}\text { Window } \\
\text { Windscreen } \\
\text { Mirror } \\
\text { Door handle } \\
\text { Door } \\
\text { Ceiling/roof }\end{array}$ \\
\hline
\end{tabular}

\subsubsection{The operations}

Analysis of the videos made it possible to define twelve main operations for basic coding. From the ontological viewpoint, the empirical data are classified according to < Type of operation>. Two strategies used by the participant were identified:

- <use>: The subject simulates situations of utilisation and the interaction "accidentally" feeds back local information via the senses, permitting the emergence of qualities specific to the object. This is typically the case when the participant changes gear, for example.

- <control>: The subject voluntarily places themselves in a situation of control. Without losing sight of projecting themselves in a situation of more or less real utilisation, they inspect and sensorially examine a specific aspect of the object so as to refine their perception of a particular quality. The participant can, for example, stroke the seat to obtain a tactile feeling of its texture.

Table 2 summarises the distribution of the main basic operations according to these two categories. 


\begin{tabular}{cll}
\hline «coding category> & \multicolumn{2}{l}{ <modality } \\
\cline { 2 - 3 } Types of operation & Use & Control \\
\hline Basic operations & Adjusting & Observing \\
& Getting out & Tapping \\
& Getting in & Touching \\
& Closing & Checking closing \\
& Handling & Checking driving position \\
& Opening & \\
\hline Table 2. & Sitring down & \\
& Distribution of basic operations by analysis category
\end{tabular}

\subsubsection{Verbalizations}

Initially, the basic coding of the verbal units was performed in parallel by two authors and the results were regularly compared. Convergence was observed after five participants, a, i.e. the authors agreed on the coding and no new basic descriptor was added. The rest of the coding was therefore accomplished by a single author.

The basic descriptors were then analysed, consciously influenced by a theoretical framework based on the ecology of perception ([29]), enactive perception ([30]) and the phenomenology of perception ( [31],[32],[33]). Other interesting theories, more familiar to designers, are discussed in [1]. The signification of the descriptors thus leads to two main categories, that is to say descriptive qualities and evaluative qualities that reveal two complementary aspects of the perceptual process. A third category, perceptual coherence, was also extracted from the examination of empirical data. Table 3 summarises the distribution of the basic descriptors according to the different categories of analysis described below.

\section{Description}

Descriptive qualities bring to light the integration process of sensorial invariants, the perceptual trigger that permits the discrimination and identification of an object. Although perceived as intrinsic to the material stimulus, they are always relative to and dependent on the subject, since they are built subjectively within the sensory motor loop (e.g. : hot (tactile), loud (audio), blue (visual)).

\section{$\underline{\text { Evaluation }}$}

The description of the perception of pragmatic meaning here takes precedence over the description of the sensation of a shape. Bearing in mind Gibson's affordances ([29]), or rather Norman's perceived affordances ([35]), this entails that the subject evaluates the potentialities offered to them by a specific object in a specific situation. The evaluative qualities are here defined in the larger framework of interaction. They have a positive, negative or neutral valence and refer to the effect on the perceiving subject or the object in question. As qualities evaluating the potential interaction between the perceiving subject and the object of their perception, they are often expressed by propositions or derivatives stemming from verbs, thereby expressing the action of the object on the subject (stressful, annoying, pleasant, etc.) or the subject's action on the object (breakable, easy to handle, etc.), or they can be linked to a synonym having this form itself. Some examples of these evaluative qualities are burning (tactile), annoying (audio) or beautiful (visual).

Whereas interaction is the process of reciprocal or combined actions between two entities, perception itself focuses on the detection of these potential interactions:

- potential actions through the object, the use provided to the subject;

- potential affects for the subject when using the object; 
- potential effects on the object in response to use.

The types of interactions determine corresponding types of expectations and thus their evaluation in the form of situated meanings in the perceptive process. There are combined influences of the behavioural, the visceral and the reflexive ([35]) in the judgement of any advantages/disadvantages linked to the interaction with the product. Nonetheless, the following types of evaluative qualities can be distinguished:

- $\quad$ use qualities: functions provided by the object to the user in a real situation. These are the qualities that interest ergonomists in particular;

- $\quad$ affective qualities: expressions of the object's impact on the sensible subject. Here they are confounded with those that were termed hedonic, as in our study most of the verbalizations recorded for this category refer to sensory pleasure. In other cases, it would be possible to identify different types of affective quality, such as emotions (e.g. "It scared me") and even physiological affections (e.g. "I could hurt myself");

- material qualities: descriptions of the presumed physical response of the object to the actions of use and the constraints potentially imposed by the subject's activity. They are different from descriptive qualities as they take on an implicit judgement value. Customers rely both on their sensations and on cognitive frameworks. However, it should be mentioned that the material evaluation of an industrial product is considerably driven by reflexive meanings, such as brand image ([36]).

Consequently, the category of evaluative qualities was divided into three sub-categories, $<$ use > qualities, <hedonic> qualities, and <material >qualities.

\section{Coherence}

This category groups the descriptors that evaluate perception itself, in terms that evoke perceptual coherence or the detection of variances in comparison to the subject's local and global expectations. Since it does not take up a large part of the discourse, this category will not be discussed in this article though deserves mention as it may play a decisive role in the global evaluation of the car.

\begin{tabular}{|c|c|c|c|c|c|c|c|c|}
\hline \multirow{2}{*}{$\frac{\langle\text { Coding category }>}{\text { Types of perception }}$} & \multicolumn{8}{|l|}{$<$ modality $>$} \\
\hline & Description & & & Evaluation & & & Coherence & \\
\hline $\begin{array}{l}\text { Natures of qualities } \\
\text { Basic descriptors }\end{array}$ & $\begin{array}{l}\text { Elementary } \\
\text { Large } \\
\text { Heavy } \\
\text { High } \\
\text { Soft }\end{array}$ & $\begin{array}{l}\text { Expressive } \\
\text { Gentle } \\
\text { Serious }\end{array}$ & $\begin{array}{l}\text { Not specified } \\
\text { Good }\end{array}$ & $\begin{array}{l}\text { Hedonic } \\
\text { Pleasant }\end{array}$ & $\begin{array}{l}\text { Material } \\
\text { High quality } \\
\text { Well finished } \\
\text { Robust } \\
\text { Richly furmished } \\
\text { Adapted material }\end{array}$ & $\begin{array}{l}\text { Use } \\
\text { Practical } \\
\text { Useful } \\
\text { Easy to use } \\
\text { Functional }\end{array}$ & $\begin{array}{l}\text { Local } \\
\text { Homogeneous } \\
\text { Salient }\end{array}$ & $\begin{array}{l}\text { Global } \\
\text { Standard } \\
\text { Advanced }\end{array}$ \\
\hline
\end{tabular}

\subsection{Quantitative analysis}

In this part, an overview of quantitative results on the global perceptual dynamics of customers is presented. Statistical analyses were performed using SPSS and R-project. ANOVAs for repeated measures (on $\langle V 1\rangle$ and $\langle V 2\rangle$ ) were used to detect discriminative inter- or intra-participant factors. Duncan's test was used as a post-hoc procedure for multiple comparisons. It should be noted that all the significant differences presented in this article are observed with a risk of $5 \%$. 


\subsubsection{Global activity}

The total activity of exploration of the two vehicles lasts an average of $18 \mathrm{~min} 07 \mathrm{~s}$ for 181 operations. Significant differences can be observed for the factors <vehicle>, <gender> and $<$ type of operation>.

The exploration of $\langle V 1\rangle$ lasted longer than that of $\langle V 2\rangle(p=0,042): 9 \mathrm{~min} 35 \mathrm{~s}$ vs. 8min 32 s. Therefore it led to more operations on average than $\langle V 2\rangle(p=0,038): 96$ vs. 85.

The men explored the vehicles for longer periods than the women $(p=0,028): 11 \mathrm{~min} 37 \mathrm{~s}$ vs. $7 \mathrm{~min} 06 \mathrm{~s}$. They therefore carried out more operations on each vehicle than the women $(p=0,005): 113$ vs. 68 .

On average on each of the vehicles, the participants spent more time $(p<0,001)$ carrying out <control> operations (5 min 50s) than < use > operations ( 3 min 10s). On the contrary, the average number of operations per vehicle of each of these categories was the same (45).

\subsubsection{Global discourse}

A significant difference $(p=0,006)$ was observed between the production of verbalizations from the men, on average 134 verbal units, and the women, on average 82 verbal units. The average for all the participants was 112 verbal units. This average therefore serves as the reference for normalizing the numbers of verbal units (VU) and the percentages expressed in the rest of this article.

A significant difference was found for the factor <vehicle $>(p=0,001)$, with $62 \mathrm{VU}$ for $\langle V 1\rangle$ and $50 \mathrm{VU}$ for $\langle V 2\rangle$. Figure 3 shows the average distribution of the verbal units according to the type of perceived qualities expressed. It can be seen that the <evaluation> qualities make up a significant majority.

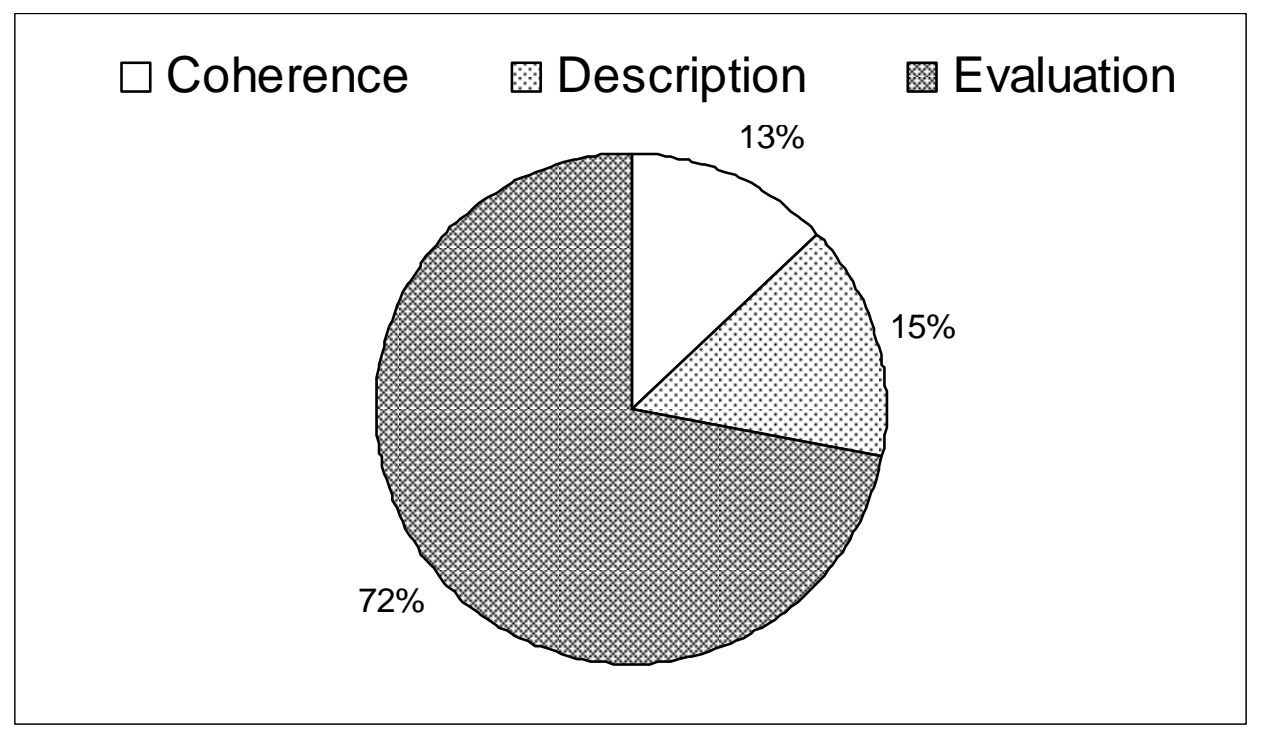

Figure 3. Average distribution of different types of perceived quality in the discourse of a participant

Regarding the evaluative type verbalizations, $22 \%$ of the participants did not communicate the criteria used for the value judgement (e.g. "I like that a lot"). As for the clearly expressed evaluative qualities, on average the participants spoke of the following qualities in decreasing importance: 〈use> $(43.8 \%)$, <hedonic > $(36.6 \%)$, followed by <material> $(19.6 \%)$.

Several significant differences were found within this category, according to the <vehicle> and < gender $>$ factors. The difference in total volume between the two vehicles was therefore due to the difference observed for $\langle u s e\rangle$ qualities $(p<0,001)$, with $\langle V I\rangle$ obtaining $19 \mathrm{VU}$, vs. $14 \mathrm{VU}$ for $\langle V 2\rangle$. Women expressed themselves more on $\langle$ hedonic $\rangle$ qualities $(p=0,036)$, with $15 \mathrm{VU}$ per vehicle vs. $11 \mathrm{UV}$ for men. This difference is entirely based on <visual> 
aesthetics $(p=0,002)$ : 10 VU per vehicle were observed for women vs. 6 VU for men. In addition, <visual> aesthetics is also the <hedonic> quality with a significant majority in the discourse ( $p<0,001$ for all comparisons performed with Duncan's multiple range test).

The <material $>$ quality is the evaluative quality for which the participants went into the least detail, and it was most often expressed globally ("ironmongery", "that's not what I'd call quality").

\subsubsection{Activity and discourse on vehicle space}

Figure 4 represents the average distribution of the volume of the verbalizations and the average distribution of the duration of the operations, according to their nature and the targeted main part. Nearly half the operations performed by the participants concerned the interior. Logically, most of the operations focused on $\langle u s e\rangle$ but a large proportion concerned $<$ control $>$ operations. The interior grouped about $70 \%$ of the evaluative qualities. The three types of evaluation are well represented. The exterior of the vehicle was almost exclusively explored by control operations, essentially via visual observation. It was mainly evaluated on the basis of visual hedonic qualities. The boot and engine are logically linked to 〈use > qualities. Regarding the boot, the qualities were often derived from $\langle$ use $\rangle$ operations. The participants mostly opted for visual <control> operations to express themselves on the engine's <use> qualities.

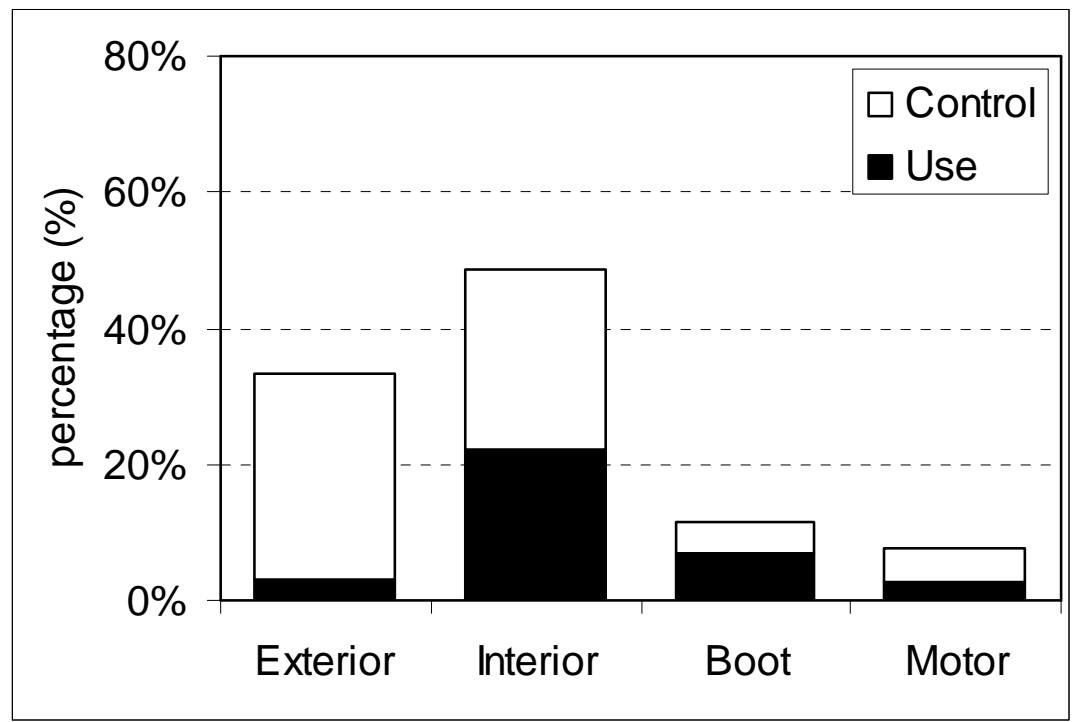

Figure 4. Mean Distribution of the duration of the operations (on the left) and of the volume of verbalizations (on the right) according to their nature and targeted vehicle main part

\subsubsection{Verbal profile of vehicles according to the participants' preference}

A verbal profile of a product consists in plotting average verbal trends for different categories of verbal analysis linked to the product. Since the difference of average verbal trend for all the participants showed a significant difference only for the <hedonic > quality $(p=0,019)$, it was decided to build the verbal profiles of the vehicles observed, by two groups of participants ordered according to their <choice> of preferred vehicle. Figure 5 represents the average verbal trends of the evaluative categories calculated for the participants of each group of preference $(\langle V 1\rangle$ and $\langle V 2\rangle)$ with confidence intervals for a risk of $5 \%$. It should be mentioned that in the hypothesis of a purchase, $60 \%$ of the participants would choose $\langle V 1\rangle$ versus $40 \%$ for $\langle V 2\rangle$. The interaction of the intra-participant factor <vehicle $\rangle$ and the interparticipant factor <choice> results in significant differences regarding average verbal trends observed for each of the evaluative categories $(p(u s e)<0,001 ; p$ (material $)=0,009$; 
$p$ (hedonic) $<0,001)$. In fact, regarding each vehicle, there are significant differences in function of the factor <choice>, for most of the average verbal trends. The exception is for the $\langle$ material $\rangle$ quality of $\langle V I\rangle$, which is not evaluated as being different from one group to another $(p=0,065)$.
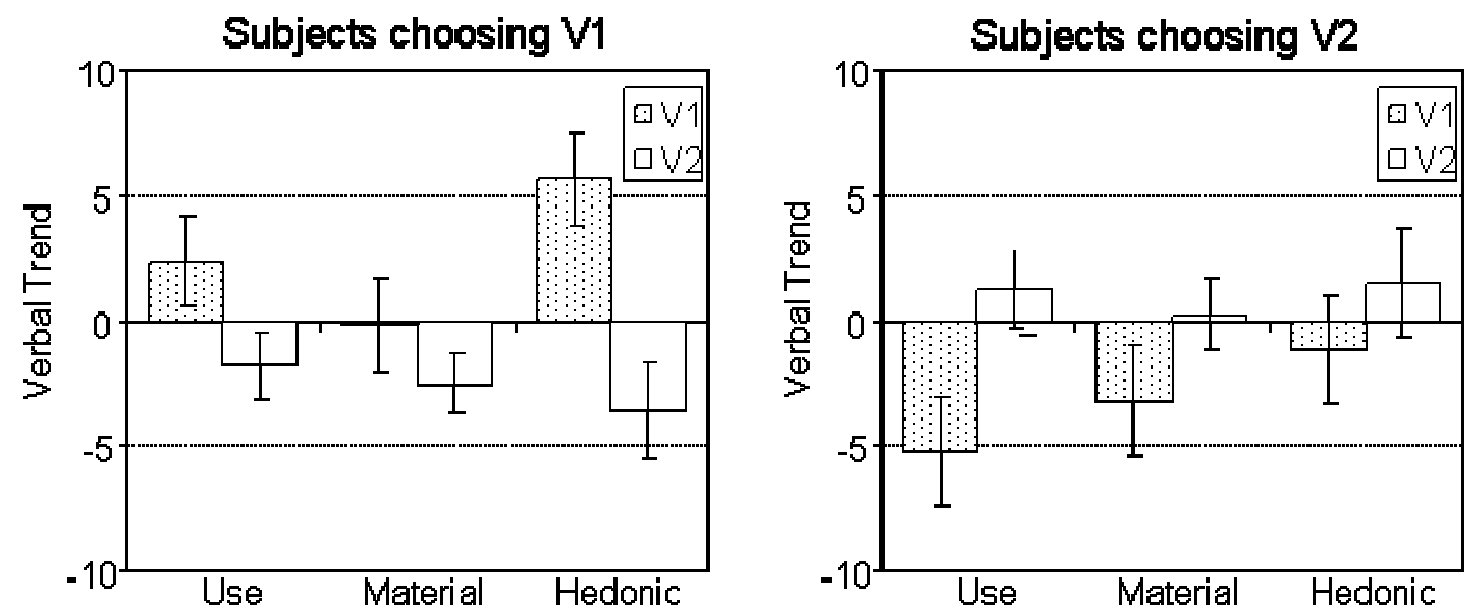

Figure 5. Verbal profiles of vehicles for each preference group

It is also possible to analyse these qualities perceived at a lower level of analysis. Without going into detail, several results can be presented. Regarding the factor <vehicle>, it can be seen that the $\langle$ visual $\rangle$ hedonic quality remains to the advantage of $\langle V I\rangle$ whatever the choice made by the participants, with a significant difference $(p=0,001)$. The quality of the $<$ matter >, a detailed aspect of the material quality, is always judged as being less good in $\langle V 1\rangle$, whatever the participant's final preference $(p=0,004)$.

Regarding the other types of discriminative qualities, there are significant differences as a function of the interaction <choice $* *$ vehicle>. For example, the <seating comfort> $(p=0,001)$ and the impression of $\langle$ space $\rangle(p=0,001)$ showed significant differences, with a positive valence for the preferred vehicle and a negative valence for the other.

Naturally the database also provides the opportunity of investigating evaluative qualities linked to 〈use $\rangle$, although this aspect is not dealt with in this study.

\subsubsection{The effect of first impression}

Through the $\chi^{2}$ test of independence, a significant correspondence $(p=0,001)$ was found between the vehicle judged positively during the first evaluative comparison, whatever the type of judgement, and the vehicle finally chosen by the participant. This gives weight to the adage "it's the first impression that counts". The contingency table is given below (see table 4).

\begin{tabular}{lllll}
\hline & & \multicolumn{2}{l}{$\begin{array}{l}\text { First evaluative } \\
\text { comparison }>\end{array}$} & Total \\
\cline { 3 - 5 } & & $\langle V 1\rangle$ & $\langle V 2\rangle$ & \\
\hline <choice $>$ & 24 & 7 & 31 \\
& $\langle V 1>$ & 8 & 13 & 21 \\
Total & 32 & 20 & 52 \\
\hline
\end{tabular}

Table 4. Table of contingency between the vehicle chosen by the participant and that preferred in the first comparison. 


\section{The sound of tapping on the dashboard}

After having given a glimpse of the analysis allowed by the data collected during observation, we now focus on analysing the act of tapping on the dashboard and its perception through the auditory dimension.

\subsection{Objects targeted by the auditory dimension}

A limited number of objects generate a verbal reference to sound (see figure 6). Three objects stand out from the others: the <door >, the <dashboard> and the <storage boxes>, all three of them in proportions that are not significantly different for the number of participants or the number of verbal units. The dashboard is therefore one of the privileged targets in the auditory dimension. It is interesting to note that the door did not generate more verbalisations despite that fact that all the participants were obliged to enter the vehicle. Moreover, it should be mentioned that it was impossible to identify a group of participants that were specifically interested in the sound dimension. In fact, it was not the same individuals that talked about one sounding object or another.

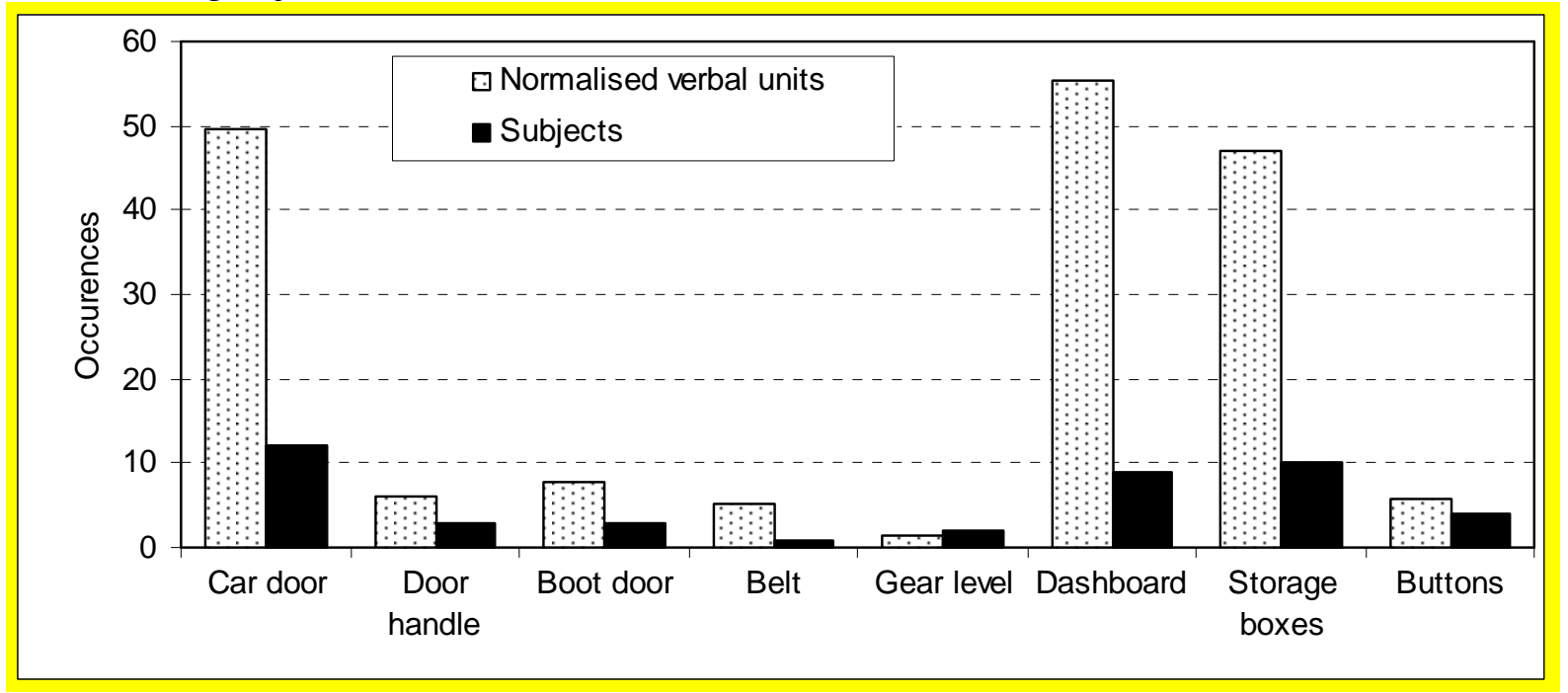

Figure 6. Distribution of verbal units explicitly linked to the auditory dimension.

\subsection{Operations on the dashboard}

Since the storage compartments are dealt with separately, the dashboard exclusively generates

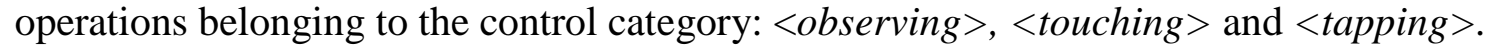

Most of the participants went no further than <touching > the dashboard but the operation of tapping on the dashboard is not anecdotal. $20 \%$ of the participants tapped on the dashboard of $\langle V 2\rangle$ at least once and up to $27 \%$ tapped on the dashboard of $\langle V 1\rangle$. These proportions are comparable to those of the participants who neither touched nor tapped. Those who tapped on the dashboard of $\langle V 1\rangle$ did not necessarily tap on that of $\langle V 2\rangle$, and vice-versa. Consequently, a total of 19 out of 52 participants, i.e. nearly $36 \%$, tapped on one or the other vehicle. Of this number, only 6 participants, i.e. $12 \%$, tapped on the dashboards of both vehicles. Figure 7 shows the distribution of the participants according to three groups of <behaviour> for each of the vehicle. 


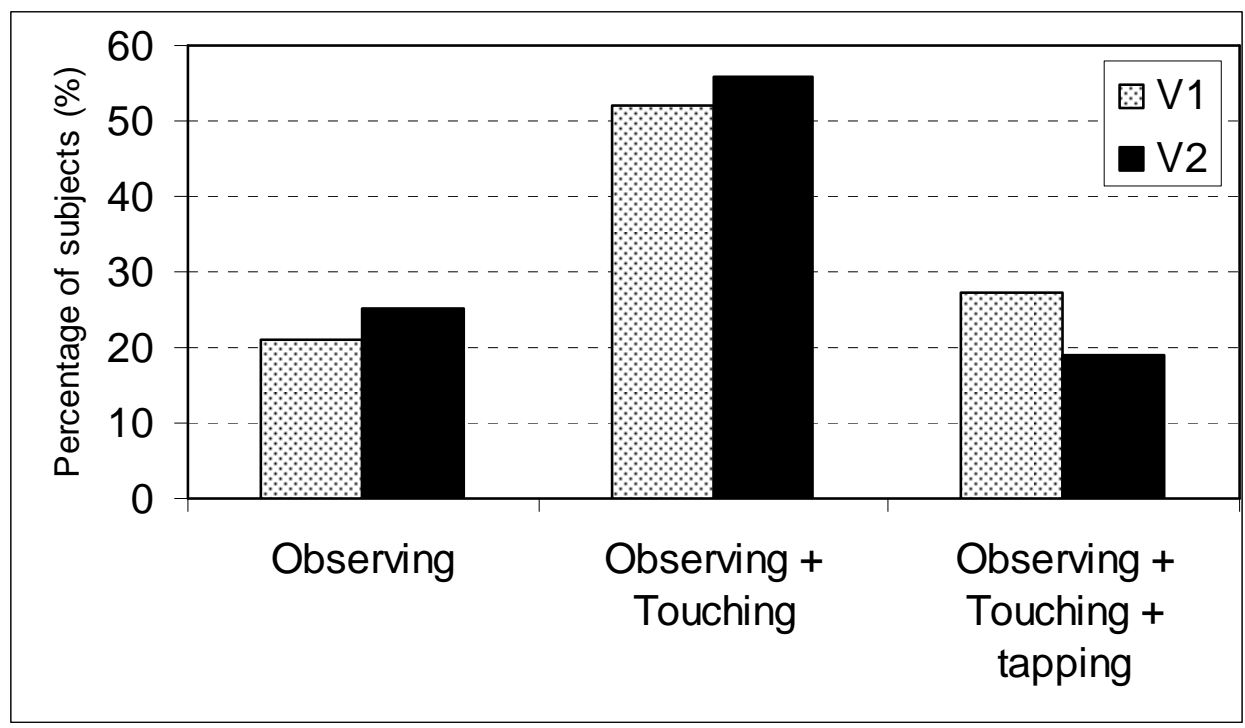

Figure 7. Distribution of participants according to the control operation on the dashboard.

\subsection{Subjective evaluation of the dashboard}

On average the participants expressed six verbal units on the dashboard of each vehicle. The <material> qualities elicited the largest number $(2.7 \mathrm{VU})$, followed by the number of $<$ hedonic> qualities (1.7 VU). The average number of <use > qualities was almost nil, as the storage compartments were treated as distinct objects.

The difference of <material> evaluation, always revealed by the bias of the associated verbal trend $T$, appeared significant $(p=0,002)$ between the two vehicles for all the participants when focusing specifically on $\langle$ matter $\rangle$. The matter of $\langle V 1\rangle$ was judged to be of poorer quality $(T=1.7)$ than that of vehicle $2(T=0.2)$.

Furthermore, all the evaluative qualities referring to both the dashboard and the auditory dimension expressed the <material> quality of <matter $\rangle$. It was therefore sought whether the act of tapping and the resulting sound had an impact on this evaluative quality.

\subsection{Link between operation and evaluation}

Figure 8 shows the average verbal trend calculated for the < material> quality linked to the $<$ matter > of the dashboard, as a function of the different groups of behaviour and for each of the cars. Confidence intervals are shown.

For $\langle V 1\rangle$, the perceived quality of the dashboard material is subject to a significant effect of the <behaviour> variable $(p=0,02)$. The judgement of participants who had tapped on the dashboard was far more severe than those who merely looked at it $(p=0,006)$. For vehicle 2 , the evaluation did not fall significantly. The act of tapping is discriminative since it accentuates the difference of the evaluation, which becomes very significant between the two vehicles $(p<0,01)$. 


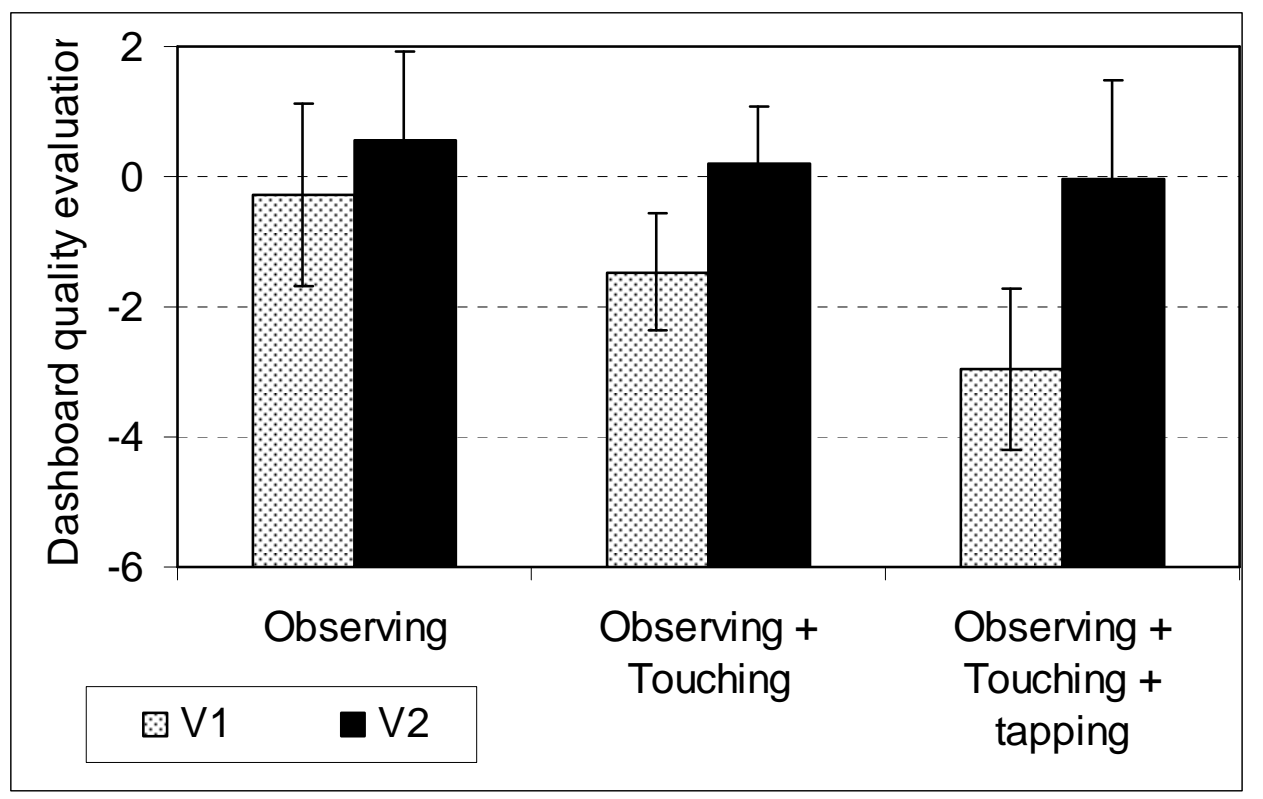

Figure 8. Dashboard material quality evaluation of the 2 vehicles by 3 behavioural groups of participants

\subsection{Discussion}

It is difficult to fully take account of the absolute influence of sound. The behaviour of the participants differed according to vehicle, as they tapped on the dashboard of $\langle V I\rangle$ more often. This suggests that the dynamics of the exploration led them to the act of tapping for this vehicle in particular, for which the quality of the matter was judged to be lower. It is therefore possible that some participants simply wanted their suspicions to be confirmed. The former perception, which was already negative when based on vision and touch, was not changed by the intake of the auditory dimension. The difference of value assigned to the trend therefore stems from those who go as far as tapping and it is these participants who were already the most critical regarding the specific aspect of the dashboard's material quality.

However, the opinions of the group of participants that tapped on the other vehicle were not as negative. The difference of the evaluation cannot therefore stem exclusively from a difference of sensitivity among the participants. What is more, the material reality made accessible by the sound of tapping plays a role. It can therefore be considered that access to the auditory dimension contributes new local information that biases the participants' judgement. In this case, the individuals that had tapped without any specific aim of discerning quality received the stimulus necessary to obtain a global, multimodal and synthetic evaluation of the quality of the matter composing the dashboard. Thus they adjusted their perceptual image integrating auditory information. Finally, these two factors, the individual sensitivity and sensorial information, coexist in a theoretical model of perceptual dynamics. The latter permits the construction of a perceptual image, a priori projected by the subject through their individual expectations that are continually adjusted by their confirmation or correction, via the incorporation of new sensorial data.

Fully understanding of the relative effect of each modality may be provided by studies such as [38], although we hitherto assume that material quality perceived from the sound of tapping on the dashboard constitutes a relevant perceptual criterion for the design process. A satisfaction model for the materials used to upholster passenger car interiors should definitely include the act of tapping, and therefore the auditory dimension, in order to obtain a complete view of customers' perception . 


\section{Conclusion}

\subsection{Activity and perception of potential customers}

The observations carried out here allowed collecting a large amount of audiovisual data on the perceptual dynamics in play during the exploration of an immobile vehicle. Coding categories were then formulated to represent and analyse empirical data from a qualitative and quantitative point of view.

The key, synthetic notion that stems from the study is the evaluation of potentials of interaction. Indeed, the activity of exploration does not correspond to a use situation in particular. The aim is that it should be carried out as exhaustively as possible in relation to the expectations of a subject who successively projects themselves in different potential use situations, while reserving a considerable part of their activity for the reception of stimuli, by carrying out conscious and unconscious control operations. The aim of these projections is to efficiently evaluate the product's advantages and disadvantages in the case of daily interaction. These evaluations are expressed through use, and the hedonic and material qualities attributed to the whole product or to subparts of it.

We suggest that this collection method and analysis framework could form a useful basis for studies aimed at observing potential customers confronted by a product. The study of perceived qualities allows the investigation of usability and affections. Moreover, grounded data on these three subjective dimensions can be useful for different approaches related to human factors, such as usability [3], kansei engineering [2] and quality management [5]. Further refinement is possible of categories of analysis of specific phenomena, depending on specific centres of interest based on hypotheses made beforehand or which are suggested by the data.

\subsection{The dashboard tapping sound}

The present article served to give a global view of the activity and perception of a customer seeking to assess a vehicle. The coded data formed a base which could be explored to study different aspects of the perceptual dynamics involved. In this case, emphasis placed on the act of tapping on the dashboard of a car satisfied the first aim of the study, which was to determine the influence of the noise made by this action on perception.

During the static exploration of the vehicle, it appeared that a large number of participants carry out this action spontaneously. Consequently, it is inevitable that this action occurs in showrooms and at car dealers. The quality perceived through the sound emitted by a dashboard when tapped was then identified. What is at stake is not the pleasure of listening to a sound, but the material evaluation, albeit subjective, of the reliability of the matter composing the dashboard. Furthermore this quality can be perceived through the synthesis of several sensorial modalities [visual, tactile, auditory] corresponding to successive operations [observing, touching, tapping]. It was determined that within this perceptual dynamics, the auditory modality could play a significant role, by lowering the evaluation of the dashboard.

These results validated the advantage car manufacturers can obtain by mastering the sound emitted by the dashboard when tapped, to ensure that the customer's perception of the vehicle examined is optimal.

By determining the nature of the quality perceived in a realistic situation, subsequent work can now be centred on an appropriate perceptual criterion. The next step of the design process centred on sound perception is to objectify the subjective evaluation as a function of the acoustic characteristics of noise, to check existing dashboards and prototypes. It is also possible to build satisfaction models as a function of the physical characteristics of the dashboard, so as to propose relevant design solutions. This can be accomplished through 
subjective experiments in the laboratory, where subjects will be questioned on the perceived material quality evoked by tapping sounds recorded on a set of dashboards. However, it should not be forgotten that sound is an additional piece of information that the customer integrates in their multisensory process, after vision and touch. It is therefore necessary to carry out a multimodal synthesis in order to enhance knowledge of how customers perceive a dashboard.

\section{Acknowledgements}

This study was founded by the car manufacturer Renault. The authors are grateful to Dr. Daniel Nesa for his support.

\section{References}

[1] N. Crilly, J. Moultrie, P.J. Clarkson, Seeing things: consumer response to the visual domain in product design, Design Studies 25 (6) (2004), pp.547-577.

[2] M. Nagamachi, Kansei Engineering: A new ergonomic consumer-oriented technology for product development, International Journal of Industrial Ergonomics 15 (1) (1995), pp 3-11.

[3] International Organisation for Standardisation, ISO 20282 : Ease of operation of everyday products, Geneva, 2006.

[4] K. Krippendorff, R. Butter, Product semantics: exploring the symbolic qualities of form. The Journal of the Industrial Designers Society of America (1984), pp.4-9.

[5] E.F. Stone-Romero, D.L. Stone, D. Grewal, Development of a multidimensional measure of perceived product quality, Journal of Quality Management 2 (1) (1997), pp.87-111.

[6] S.-H. Hsu, M.-C.Chuang, C.-C. Chang, A semantic differential study of designers' and users' product form perception, International Journal of Industrial Ergonomics 25 (4) (2000), pp.375-391.

[7] M.-C. Chuang, C.-C. Chang, S.-H. Hsu, Perceptual factors underlying user preferences toward product form of mobile phones, International Journal of Industrial Ergonomics 27 (4) (2001), pp.247-258.

[8] C.-C. Chang, Factors influencing visual comfort appreciation of the product form of digital cameras, International Journal of Industrial Ergonomics 38 (11-12) (2008), pp.1007-1016.

[9] H.-C. Chang, H.-H. Lai, Y.-M. Chang, Expression modes used by consumers in conveying desire for product form: A case study of a car, International Journal of Industrial Ergonomics 36 (1) (2006), pp.3-10.

[10] T.Jindo, K. Hirasago, Application studies to car interior of Kansei engineering. International Journal of Industrial Ergonomics 19 (1997), pp. 105-114.

[11] H.N.J. Schifferstein, The perceived importance of sensory modalities in product usage: A study of self-reports, Acta Psychologica 121 (1) (2006), pp.41-64.

[12] A.Fenko, H.N.J. Schifferstein, P.Hekkert, Shifts in sensory dominance between various stages of user-product interactions, Applied Ergonomics, In Press, Corrected Proof, Available online 29 April 2009.

[13] E. Parizet, E. Guyader, V. Nosulenko, Analysis of car door closing sound quality, Applied Acoustics 69 (1) (2008), pp. 12-22. 
[14] H. You, T. Ryu , K. Oh, M.-H. Yun, K.-J. Kim, Development of customer satisfaction models for automotive interior materials, International Journal of Industrial Ergonomics 36 (4) (2006), pp. 323-330.

[15] G. Clouet, Evaluation ergonomique de produits et de services : Le cas du web marchant. Thèse de doctorat. Ergonomie, Université Paris 8, Saint-Denis, 2005.

[16] N. Stanton, M. Young, Is utility in the mind of the beholder? A study of ergonomics methods, Applied Ergonomics 29 (1) (1998), pp.41-54.

[17] D. Marsden, D. Littler, Exploring consumer product construct systems with the repertory grid technique, Qualitative Market Research: An International Journal 3 (3) (2000), pp.127-144.

[18] V. Nosulenko, V.A. Barabanshikov, A.V. Brushlinsky, P. Rabardel, Man-technology interaction : some of the Russian approaches, Theoretical Issues in Ergonomics Science 6 (5) (2005), pp. 359-383.

[19] V. Nosulenko, E. Samoylenko, Approche systémique de l'analyse des verbalisations dans le cadre de l'étude des processus perceptifs et cognitifs, Social science information 36 (2) (1997), pp. 223-261.

[20] S. Lahlou, V. Nosulenko, E. Samoylenko, Un cadre méthodologique pour le design des environnements augmentés, Social science information 41 (4) (2002), pp. 471-530.

[21] V. Nosulenko, Psychological Peculiarities and Acoustical Environment Changes, International Journal of Psychology 6 (5) (1991), pp 623-632.

[22] E. Samoylenko, S. McAdams, V. Nosulenko, Systematic Analysis of Verbalizations Produced in Comparing Musical Timbres, International Journal of Psychology 31 (6) (1996), pp. 255-278.

[23] V. Nosulenko, E. Samoylenko, E. Parizet, Evaluation and verbal comparison of noises produced by car engines, International Journal of Psychology 31 (1996), pp. 3-4.

[24] B.G. Glaser, A.L. Strauss, The Discovery of Grounded Theory: Strategies for Qualitative Research, Aldine de Gruyter, New York, 1967.

[25] B.G. Glaser, Emergence vs. Forcing: Basics of Grounded Theory Analysis, Sociology Press, Mill Valley, 1992

[26] B.G. Glaser, Doing Grounded Theory: Issues and Discussions, Sociology Press, Mill Valley, 1998

[27] A.L. Strauss, J. Corbin, Basics of Qualitative Research. Grounded Theory : Procedures and Techniques, Sage, Newbury Park, 1990.

[28] U. Kelle, "Emergence" vs. "Forcing" of Empirical Data? A Crucial Problem of "Grounded Theory" Reconsidered, Forum: Qualitative Social Research [On-line Journal], 6(2) (2005), Art. 27.

[29] J.J. Gibson, The theory of affordances, in The ecological approach to visual perception. London : Lawrence Erlbaum Associates, 1986.

[30] A. Noe, Action in Perception, The MIT Press, Cambridge, 2004.

[31] E. Husserl, Idées directrices pour une phénoménologie, Gallimard, Paris, 1913.

[32] M. Merleau-Ponty, Phénoménologie de la perception. Gallimard, Paris , 1945.

[33] V. Havelange, Acte intentionnel, perception et sensation dans la phénoménologie Husserlienne : chair et objet technique. Proceeding of Séminaire Interdisciplinaire sur la Cognition : Espaces de perception, Espaces d'action, Compiègne, 2003.

[34] D.A. Norman, The psychology of everyday things, Basic Books, New York, 1988.

[35] D.A. Norman, Emotional design : Attractive things work better, Basic

Books, New York, 2004.

[36] P.M. Homer, Perceived quality and image: When all is not 'rosy', Journal of Business Research 61 (7) (2008), pp. 715-723 
Int. J. of Industrial Ergonomics 40 (2010), 592-603

[37] H.N.J. Schifferstein, M.P.H.D. Cleiren, Capturing product experiences: a split-modality approach, Acta Psychologica 118(3)(2005),pp. 293-318 